\title{
Response to letter on Caroli disease
}

\author{
Venkat S. Katabathina, ${ }^{1}$ Wojciech Kapalczynski, ${ }^{1}$ Christine Menias $^{2}$ \\ ${ }^{1}$ UT Health Science Center at San Antonio, San Antonio, TX, USA \\ ${ }^{2}$ Mayo Clinic, Scottsdale, AZ, USA
}

\section{Dear Drs. Ozum Tuncyurek and David Lomas:}

Thank you for your commentary/letter. We agree that the classification of Caroli disease in the Todani system needs to be looked at very carefully. The first reason being, while widely accepted as part of the Todani classification system for choledochal cysts, it is important to recognize that Caroli disease is a separate disease entity, with very different theories of etiology [1]. Caroli disease is part of the clinicopathologic spectrum of ductal plate malformations, which occur when there is disruption of the embryologic remodeling of the ductal plate resulting in the persistent ductal structures [2]. In contrast, while the exact etiology of the other choledochal cysts is still unclear, most theories share the idea that intraductal pressure surpassing the yield strength of the bile duct leads to choledochal cyst formation.

The second reason is more to do with the practicality of the Todani system. With the publication of new case reports and proposed further sub-classification (type VI, "forme fruste", etc.), it is easy to see how the alphanumeric system proposed above is getting to be increasingly complex and user unfriendly. Consequently, an increasing number of people in the scientific community are beginning to question the Todani system. Some, like you, have already proposed removing Caroli disease from the classification system.

Visser et al. have recently challenged the Todani classification system, arguing that it encompassed several loosely related disease entities with differing etiologies, natural courses, surgical options, and complication profiles. They propose that type-I and type-IVA cysts are simply variations of the same disease, citing that in their experience all type-I cysts had some element of intrahepatic involvement. Furthermore, they argue that type II lesions are just diverticula of the common bile duct more closely resembling gallbladder duplication than true choledochal cysts. They consider choledochoceles to be variants of duodenal duplication and underline the fact that, while Caroli disease resembles choledochal cysts morphologically, it has an unrelated etiopathogenesis. As a result, Visser et al. advocate that the term "congenital choledochal cyst" be used exclusively for describing congenital dilation of the extrahepatic and intrahepatic bile ducts (apart from Caroli disease) and that CBD diverticula, choledochoceles, and Caroli disease should no longer be thought of as subtypes of choledochal cysts [3]. They propose using descriptive nomenclature instead of the alpha numeric classification, and this idea has been supported by subsequent literature furthermore [4].

Lastly, removing Caroli disease from the complex Todani system may allow focus to shift away from differentiating it from the various choledochal cysts to separating it out from its far more closely related disease entities of congenital hepatic fibrosis and Caroli syndrome.

Compliance with ethical standards

Conflict of interest No conflicts of interest.

\section{References}

1. Singham J, Yoshida EM, Scudamore CH (2009) Choledochal cysts: part 1 of 3: classification and pathogenesis. Can J Surg 52(5):434 440

2. Levy AD, Rohrmann CA Jr (2003) Biliary cystic disease. Curr probl Diagn Radiol 32(6):233-263

3. Visser BC, Suh I, Way LW, Kang SM (2004) Congenital choledochal cysts in adults. Arch Surg 139(8):855-860 (discussion 60-62)

4. Wiseman K, Buczkowski AK, Chung SW, et al. (2005) Epidemiology, presentation, diagnosis, and outcomes of choledochal cysts in adults in an urban environment. Am J Surg 189(5):527-531 (discussion 31) 